\title{
A IMPORTÂNCIA DA POLÍTICA DE COTAS PARA O AVANÇO DOS ESTUDOS DE GÊNERO A PARTIR DE PERSPECTIVAS DECOLONIAIS NO BRASIL
}

THE IMPORTANCE AFFIRMATIVE ACTIONS FOR THE ADVANCEMENT OF GENDER STUDIES FROM DECOLONIAL PERSPECTIVES IN BRAZIL

Amanda Alves da Silva *

Janja Araújo**

*Graduada em Ciências Sociais pela Universidade Federal do Recôncavo da Bahia (UFRB), mestra e doutoranda no Programa de Pós-graduação em Estudos Interdisciplinares sobre Mulheres, Gênero e Feminismo pela Universidade Federal da Bahia (PPGNEIM/UFBA) e bolsista (FAPESB). Trabalha com a temática dos estudos decoloniais na América Latina, epistemologias feministas, gênero e raça.

${ }^{\star \star}$ Professora do Departamento de Estudos de Gênero e Feminismo da Faculdade de Filosofia e Ciências Humanas da Universidade Federal da Bahia (FFCH/UFBA). Professora permanente do Programa de Pós-graduação em Estudos Interdisciplinares sobre Mulheres, Gênero e Feminismo (PPGNEIM/UFBA) e do Doutorado Multi-institucional e Multidisciplinar em Difusão do Conhecimento (DMMDC/UFBA). 


\section{RESUMO}

As lutas antirracistas se encontram nas bases de formação do pensamento e das teorias feministas para quem transita pelas trocas epistêmicas aos estudos sobre gênero e raça. A implementação das políticas de reserva de cotas para pessoas negras (pretas e pardas), denominadas cotas raciais, também repercute nos programas de pós-graduação. Isso não apenas pela participação de pessoas negras nos espaços de produção de conhecimento, mas sobretudo interferindo nesses programas (latu sensu e stricto sensu) através da filiação ao conhecimento crítico, antirracista e antissexista para refletir a colonialidade destes. Neste estudo intentamos refletir em que medida essa produção é responsável pelo aumento de pesquisas sobre os feminismos autoproclamados decoloniais no Brasil, incluindo o feminismo negro, através de dados sobre a produção do Programa de Pós-graduação em Estudos Interdisciplinares sobre Mulheres, Gênero e Feminismo da Universidade Federal da Bahia (PPGNEIM/UFBA), identificando a própria política de cotas raciais nos cursos de graduação como uma potência ruidosa nas recentes pesquisas sobre mulheres, gênero e feminismos.

PALAVRAS-CHAVE: cotas raciais; estudos feministas; produção do conhecimento; decolonialidade.

\section{ABSTRACT}

The anti-racist campaigns are on the basis of feminist's thoughts and theories formation for the ones who crosses the epistemic exchanges in gender and race studies. The implementation of quota reserve's policies for black people(black and brown), called racial quotas, also have repercussions in graduate programs, not only by their forms of participation in spaces of production of knowledge but, mainly, interfering in these programs (lato sensu and stricto sensu) through adherence in critical, antiracist and anti-sectarian knowledge in order to reflect the coloniality in them. This study aims to reflect the extent in which this production is responsible for increasing research on the selfproclaimed decolonial feminists in Brazil, including black feminism, through data around PPGNEIM / UFBA's production, identifying the affirmative action policies in undergraduate courses as a resounding power in recent research on women, gender, and feminisms.

KEYWORDS: racial quotas; feminist studies; knowledge production; decoloniality. 


\section{Introdução}

Antes mesmo da aprovação da reserva de vagas na pós-graduação, com início em 2017, a crescente inserção de estudantes negras/os no meio acadêmico vem, aos poucos e ainda com muitas dificuldades, modificando o perfil das universidades federais no Brasil. A criação da Lei no I2.7II/2OI2, ${ }^{1}$ também conhecida como Lei de Cotas, tem possibilitado a inserção de jovens negras e negros (e indígenas e quilombolas) entre os estudantes de baixa renda, ou que estudaram em escola pública (cotas sociais) através da reserva de vagas nas universidades federais e nas instituições de ensino técnico de nível médio do país. A lei garante o mínimo de 50\% das vagas por curso e turno para as cotas a cada processo seletivo, porcentagem que é dividida em metade para estudantes de escola pública com renda igual ou inferior a um salário mínimo e meio, e outra metade para estudantes com renda superior a um salário mínimo e meio. Nos dois casos também é levado em consideração o total mínimo de vagas à proporção de pretos, pardos e indígenas da população de cada estado, segundo o último censo do Instituto Brasileiro de Geografia e Estatística (IBGE, 2OI2).

Como um dos meios que visam à reparação das desigualdades racial e social no país, a Lei de Cotas tem uma significativa importância quando se trata do contexto sócio-histórico brasileiro, com uma maioria populacional negra, mas com universidades majoritariamente brancas. De acordo com a V Pesquisa do Perfil Socioeconômico dos Estudantes de Graduação das Universidades Federais, realizada em 20I8, consideravam-se pretos (ANDIFES, 20I9), no ano de 2003, 59,4\% dos estudantes de graduação dos IFES se consideravam brancos; 28,3\%, pardos; e apenas $5,9 \%$ se consideravam pretos. A predominância de determinado grupo racial e classe social nesses espaços de produção de conhecimento culminou (e culmina) na produção de epistemologias que atendem aos padrões da ciência moderna, a qual é caracterizada pelos pressupostos da neutralidade, da racionalidade e de uma visão eurocêntrica de mundo baseada em discursos racistas, androcêntricos e sexistas.

Por conseguinte, a inserção de novos sujeitos políticos em tais espaços de conhecimento fomenta a construção de grupos de pesquisa e de movimentos sociais que questionam o modelo positivista da ciência moderna e abrem espaço para novas epistemologias e perspectivas de mundo. Assim, com outros olhares e outras vozes que identificam um lugar de fala e trazem consigo a importância de se pensar interseccionalmente, a produção de conhecimento torna-se também um ato político pautado em críticas antirracistas e antissexistas. Soma-se a essa crítica

${ }^{1}$ Disponivel em: <http://www.planalto.gov.br/ccivil_03/_ato2011-2014/2012/lei/l12711.htm>. 
o crescimento dos estudos decoloniais no Brasil (e suas vertentes, como o feminismo decolonial), que propõem a descolonização do conhecimento e do pensamento nos países da América Latina, visto que estes apresentam um histórico de colonização e subalternização.

Assim, o presente trabalho parte de uma perspectiva decolonial para entender em que medida a inserção de novos sujeitos nas universidades brasileiras através da política de cotas pode ser responsável pelo desenvolvimento de pesquisas sobre feminismos negros, latinos e antirracistas na pós-graduação. Tomamos como universo de pesquisa as dissertações e teses defendidas no Programa de Pós-graduação em Estudos Interdisciplinares sobre Mulheres, Gênero e Feminismo que faz parte do Núcleo de Estudos Interdisciplinares sobre a Mulher, da Universidade Federal da Bahia (PPGNEIM/NEIM/UFBA). Foram analisados títulos, resumos e palavras-chave das produções encontradas pelo repositório on-line da Coordenação de Aperfeiçoamento de Pessoal de Nível Superior (CAPES) e do Catálogo de Dissertações e Teses PPGNEIM/UFBA (20I8). O presente artigo teve como proposta inicial a utilização da biblioteca virtual do Grupo Latinoamericano de Estudio, Formación y Acción Feminista (Glefas)² como base analítica para a pesquisa no intuito de comparar as referências bibliográficas utilizadas pelas/os discentes e as referências contidas nas pastas de Estudos pós-coloniais; Feminismo latino; e Feminismo e antirracismo presentes no ambiente virtual do grupo, entretanto percebemos a necessidade de modificar a metodologia para uma maior consistência dos dados encontrados.

\section{Enegrecendo as universidades}

A emergência dos estudos pós-coloniais e decoloniais apontam para a importância da descolonização do pensamento que perpassa a crítica ao modelo positivista da ciência moderna e a inserção de novos/as sujeitos/as que reivindicam lugares de fala. Tais estudos trazem para o debate a marca que os processos de dominação colonial e imperialista deixaram nos países colonizados, e denunciam o discurso falacioso de salvação e civilização que serviu de justificativa para a subalternização das populações dominadas, além da maneira violenta e repressiva de dominação utilizada pelas antigas metrópoles.

A categorização racial baseada na aparência física dos colonizados e na sua "cor" de pele foi umas das justificativas para a hierarquização e dominação dos povos. Atribuíram à classificação racial características comportamentais, intelectuais e biológicas. "A formação de relações sociais

\footnotetext{
${ }^{2}$ Glefas é um grupo formado em 2007 por teóricas feministas como Ochy Curiel, Yuderkys Espinosa-Miñoso, entre outras, que atua na formação feminista com seminários, conferências e cursos virtuais, bem como trabalha com a publicação de produções com a temática feminista decolonial e pós-colonial. Ver: <http://www.glefas.org/>.
} 
fundadas nessa ideia, produziu na América identidades sociais historicamente novas: índios, negros e mestiços [...]" (QUIJANO, 2005, p. IO7). Para o referido autor, a construção da raça foi o ponto primordial para o processo de colonização na América Latina.

Com a racialização dos povos colonizados, o colonizador europeu inventa a si mesmo. O "eu" europeu é oposto ao "outro" não europeu que, por conseguinte, não tem cultura, é irracional e primitivo. O discurso racial conferiu a legitimidade necessária para a invasão, a dominação e o genocídio indígena e escravização dos povos africanos trazidos para a América. A hierarquia social imposta por meio de tal discurso foi naturalizada e ainda é reproduzida como um tipo de controle social, colocando os/as sujeitos/as marcados/as pela racialização em um espaço marginal, destituídos/as de lugares de poder, educação e emprego.

Evidentemente o processo de escolarização de pessoas negras no país também é afetado por tais relações de poder e discriminação racial, reverberando desde a evasão de pessoas negras no ensino fundamental e médio, como também no pouco acesso desse grupo ao ensino superior, principalmente nos cursos de pós-graduação. Segundo os dados da Pesquisa Nacional por Amostra de Domicílios Contínua (IBGE, 20I8), realizada em 20I7, 47,4\% das pessoas negras (pardas e pretas) não completaram a primeira etapa do ensino básico, enquanto entre as pessoas brancas a porcentagem é de $33,6 \%$. Na continuação da vida acadêmica, 22,9\% das pessoas brancas concluíram o ensino superior; entre as pessoas negras, esse número cai drasticamente para 9,3\%. Ainda que os números tenham melhorado em comparação com anos anteriores, segundo a pesquisa, a diferença de escolaridade entre brancos e negros continua grande.

A desigualdade étnico-racial no Brasil é camuflada pelo "mito da democracia racial" que, de acordo com Antônio Sérgio Guimarães (2003), nega a existência de raças e afirma que cor é um mero acidente, de modo a evidenciar que não há qualquer tipo de discriminação racial no país. $\mathrm{Ou}$, então, justifica-se as desigualdades apenas pelo viés econômico, desconsiderando que as discriminações de raça, classe e gênero andam juntas. Dessa maneira, o fator classe social acrescenta mais um véu ao preconceito racial dos brasileiros, mas isso é uma discussão para um próximo artigo.

Durante a década de 1970 a luta do movimento negro contra a discriminação racial e pela igualdade de direitos ganhou maior visibilidade. Tal movimento teve um importante papel ao explicitar que a desigualdade racial não era simplesmente o fruto de um passado escravocrata, mas fazia parte de uma construção social mais complexa; além do mais, passou a ressignificar e politizar a ideia de raça no Brasil (GOMES, 20I7). Em 200I, foi realizada na cidade de Durban, África do Sul, a Conferência Internacional contra o Racismo, Discriminação Racial, Xenofobia e 
Formas Correlatas de Intolerância, que possibilitou grandes avanços na luta contra a discriminação racial no país. Ao longo da conferência foram criadas propostas para a implementação de políticas sociais que visavam ao enfrentamento da discriminação e da promoção da igualdade racial. O governo brasileiro se comprometeu a adotar medidas de prevenção e combate à desigualdade. De acordo com Paula Barreto (2008, p. 25),

[...] a ação afirmativa deixou, paulatinamente, de ser uma reivindicação presente apenas no discurso de militantes antirracistas, para fazer parte da agenda de intelectuais, cientistas sociais, jornalistas, lideranças de partidos políticos, líderes comunitários, participantes de diversos movimentos sociais e representantes de órgãos governamentais, entre outros atores importantes, começando a se formar uma corrente de opinião pública sobre o assunto.

No entanto Barreto (2008) chama atenção para o fato de que o reconhecimento e o comprometimento do governo e da sociedade brasileira com as causas raciais foram frutos de décadas de luta dos movimentos antirracistas e do movimento negro no país. Assim, o governo adotou políticas de ações afirmativas como um meio de reparação sócio-histórica. De acordo com Arabela Oliven (2007, p. 30), entende-se como ação afirmativa:

[...] um conjunto de políticas públicas para proteger minorias e grupos que, em uma determinada sociedade, tenham sido discriminados no passado. A ação afirmativa visa remover barreiras, formais e informais, que impeçam o acesso de certos grupos ao mercado de trabalho, universidades e posições de liderança. Em termos práticos, as ações afirmativas incentivam as organizações a agir positivamente a fim de favorecer pessoas de segmentos sociais discriminados a terem oportunidade de ascender a postos de comando.

As ações afirmativas são temporárias porque visam supressão ou redução de desigualdades originadas da racialização da sociedade e, por conseguinte, da pobreza, influenciando sobre as oportunidades. Tomás Fernández Robaina (2005) afirma que as ações afirmativas têm caráter provisório, pois, uma vez conseguindo o equilíbrio entre os grupos sociais, sua continuidade traria a desigualdade novamente. Contudo, segundo Robaina (2005, p. 36I), "chegar a esse estado é o resultado de um longo processo que ainda não foi atingido por nenhuma sociedade".

De acordo com André Lazaro (2016), as políticas de ação afirmativa têm o intuito de superar a exclusão histórica das populações negras e indígenas ao acesso ao ensino superior, servindo também como forma de combate ao racismo estrutural do país. Para o referido autor "um dos objetivos centrais das políticas é contribuir para que jovens e adultos que representam a 
diversidade da população ingressem na educação superior e alcancem postos de decisão e poder que só podem ser ocupados a partir desse nível de escolaridade" (LAZARO, 2016, p. I32). Entretanto tais políticas foram alvo de críticas daqueles que tiveram seus privilégios contestados, cujo resultado foi que:

[...] durante os primeiros dez anos de adoção, as cotas nas universidades foram alvo de centenas de ações judiciais, movidas por estudantes que teriam se sentido lesados por tais medidas. O discurso da mestiçagem foi utilizado por esses atores sociais de uma maneira fiel aos discursos dos anos 1930, mas com uma aparência nova, pautada no Direito Constitucional e, mais precisamente, ao artigo 5을 da assim chamada "Constituição Cidadã" de 1988. O discurso se completou [...] pela defesa do mérito individual, um valor que divide a sociedade entre talentosos e que presenteia aqueles com maior acesso a bens e serviços sociais. (SILVÉRIO; MEDEIROS, 20I6, p. 86)

A política de cotas atua como um instrumento das ações afirmativas para a promoção da igualdade racial nos espaços de ensino superior no Brasil. Ainda que a Lei de Cotas tenha sido sancionada somente em 20I2, algumas universidades foram aos poucos implementando a reserva de vagas para alunos negros, indígenas, de escola pública e de baixa renda antes mesmo de sua adoção pelo estado brasileiro. A exemplo da Universidade Federal da Bahia (UFBA) que, de acordo com Santos e Queiroz (2013, p. 37), adotou o sistema de cotas em 2004,

[...] para candidatos que cursaram os três anos do ensino médio e mais um ano do ensino fundamental na rede pública de ensino. A medida estabeleceu o percentual de $43,0 \%$ das vagas para todos os cursos, e tem um diferencial em relação à condição étnico-racial do estudante: $85,0 \%$ dessa reserva, ou seja, $36,5 \%$ do total são direcionadas para os autodeclarados pretos e pardos, e $15,5 \%$ $(6,5 \%)$ aos autodeclarados não negros (brancos e/ou amarelos). Um percentual de 2,0\% é destinado aos indiodescendentes, e uma reserva de duas vagas extras, em cada curso, para índios aldeados e estudantes oriundos de comunidades quilombolas.

A reserva de vagas tem garantido não só a reparação de desigualdades étnico-raciais como também a mudança do perfil dos universitários/as no país. Bento (2005) argumenta que a população branca brasileira tem uma cota de $100 \%$ nos espaços de poder no país, que foram "construídas silenciosamente, ao longo de séculos de opressão contra negros e indígenas, e foram naturalizadas" (p. I65). Essa cota silenciosa para brancos, a qual se refere a autora, fazia-se presente 
nos espaços universitários, que também são espaços de poder, seguindo a lógica colonial, quando apenas brancos e filhos de senhores de engenho podiam acessar o ensino superior.

Em um estudo acerca da utilização da temática sobre relações raciais na produção de dissertações e teses nos programas de pós-graduação no Brasil, Amélia Artes e Jesús MenaChalco (20I7) demonstraram através dos dados coletados pelo Instituto Brasileiro de Geografia e Estatística (IBGE) que houve um aumento na frequência à pós-graduação de pessoas negras (pretas e pardas), passando de 2I.567 pessoas no a no de 2000 para 63.546 pessoas em 20IO. Ainda que seja um aumento significativo em comparação a décadas posteriores, esse número representa apenas $24,8 \%$ das vagas, porcentagem pequena quando levamos em consideração que o Brasil tem uma população de maioria negra.

Pensar nas desigualdades presentes na inserção das pessoas negras no ambiente educacional perpassa também a crítica ao sistema da colonialidade, que continua reproduzindo as hierarquias impostas durante a colonização das Américas e a exploração de povos indígenas e negros. O sociólogo peruano Aníbal Quijano (1992) utiliza dois conceitos diferentes para explicar tal situação, denominados colonialismo e colonialidade. O primeiro é caracterizado como "uma relação de dominação direta, política, social e cultural dos europeus sobre os conquistados de todos os continentes" (QUIJANO, I992, p. 437, tradução nossa) e que já foi minado. Já a colonialidade consistiria na reprodução de estruturas e hierarquias coloniais nas relações sociais e culturais do povo que foi colonizado, mesmo após os processos de independência. Desse modo, a colonização continuaria por outras vias, como, por exemplo, a colonização do pensamento. De acordo com Quijano (20IO, p. 84),

A colonialidade é um dos elementos constitutivos e específicos do padrão mundial do poder capitalista. Sustenta-se na imposição de uma classificação racial/étnica da população do mundo como pedra angular do referido padrão de poder e opera em cada um dos planos, meios e dimensões, materiais e subjetivos, da existência social quotidiana e da escala social.

A colonialidade também opera na produção do conhecimento e escolhe quem deve ou não adentrar no espaço de poder acadêmico. $O$ baixo acesso de pessoas pretas, pardas eindígenas nas universidades federais do Brasil, antes da implementação da política de cotas, refletia a discriminação racial presente na sociedade e o caráter colonizado de nossa mentalidade. Isso ficou explícito quando algumas parcelas da sociedade civil, do núcleo acadêmico e do governo argumentaram que as políticas de ações afirmativas disseminavam a discriminação racial e inferiorizavam a população negra. A descolonização nos espaços de produção de conhecimento 
teve início a partir do momento que pessoas antes excluídas adentram as universidades e os institutos federais e romperam com décadas de privilégio branco. Entretanto a diminuição da desigualdade racial no número de matrículas em cursos de graduação não significou o término da colonialidade nesses espaços. Outros espaços precisam ser conquistados, como, por exemplo, o acesso de pessoas negras e indígenas nos cursos de pós-graduação, na área docente das universidades e inclusive nas ementas dos cursos. Carvalho (20I8, p. 8I) afirma que as "cotas restritas à discência podem passar a mensagem sub-reptícia de que agora finalmente os jovens negros e indígenas terão a oportunidade de aprender com os brancos o saber que importa [...]: o saber eurocêntrico". ${ }^{3}$ Nesse sentido, o referido autor alega que, para uma verdadeira descolonização acadêmica, é necessário que autoridades negras e indígenas acessem às universidades também na condição de mestres/as e que transmitam seus saberes. É a coexistência do complexo cultural que Quijano (1992, p. 440) chamou de "racionalidademodernidade europeia, o qual foi estabelecido como um paradigma universal de conhecimento e de relação entre a humanidade e o resto do mundo" e a colonialidade, que foram decisivas para a construção do paradigma europeu e precisam ser minadas.

\section{Produção do conhecimento e descolonização do feminismo}

A luta pela descolonização do pensamento e pelo fim da colonialidade encontra forças nos movimentos feministas do sul, sejam eles pós-coloniais ou decoloniais, que criticam os pressupostos da ciência moderna e do paradigma europeu fundados na racionalidade e na produção de conhecimento através da relação sujeito-objeto, distanciando assim o/a pesquisado/a (sujeito/a), que deve atender os princípios da neutralidade e da objetividade perante o outro a ser estudado. Nesse sentido, o que se percebe é um traço fortemente individualista e que terá grande impacto na produção de um discurso etnocêntrico, em que o "eu" racional, neutro e objetivo, analisa e investiga o outro irracional, primitivo, que é o objeto de pesquisa (QUIJANO, 1992).

Ainda que os movimentos feministas advindos de uma perspectiva branca e ocidental tenham sido importantes para a crítica à ciência moderna e sua visão androcêntrica e sexista, contribuindo para a crise do paradigma europeu (MIGNOLO, 2004), tais movimentos não

\footnotetext{
${ }^{3}$ O autor utiliza o exemplo do Encontro de Saberes, disciplina implementada em 2010 na Universidade de Brasília (UnB) e depois em outras universidades, como a Universidade Federal de Minas Gerais (UFMG), Universidade Federal de Juiz de Fora (UFJF), Universidade Federal do Pará (UFPA), Universidade Estadual do Ceará (UECE), Universidade Federal do Sul da Bahia (UFSB), Universidade Federal do Cariri (UFCA), Universidade do Rio Grande do Sul (UFRGS) e Universidade Federal Fluminense (UFF), que trouxe mestres e mestras dos saberes tradicionais para o espaço acadêmico (CARVALHO, 2018).
} 
conseguiram agregar a raça como categoria fundante para a opressão das mulheres que vivem em um contexto de colonialidade. Dessa maneira, reproduzem o discurso e a opressão colonial quando constroem as "mulheres do Terceiro Mundo" como um grupo homogêneo vítima da opressão sexista, pobre, sem educação e conhecimento e que necessita constantemente de ajuda, como explicita Chandra Mohanty (20II). Para Ochy Curiel (2009, p. 3), a descolonização para o feminismo latino-americano

[...] se trata de uma posição política que atravessa o pensamento e a ação individual e coletiva, nossos imaginários, nossos corpos, nossas sexualidades, nossas formas de atuar e de ser no mundo e que cria uma espécie de "cimarronaje" ${ }^{4}$ intelectual, de práticas sociais e da construção do pensamento próprio de acordo com experiências concretas. Trata-se do questionamento do sujeito único, ao eurocentrismo, ao ocidentalismo, à colonialidade do poder, ao tempo que reconhece propostas como a hibridização, à polissemia e ao pensamento outro, subalterno e fronteiriço. Essas propostas críticas do feminismo latino-americano e caribenho são posições de oposição ao feminismo ilustrado, branco, heterossexual e estatal, mas sobretudo um feminismo que se pensa e repensa a si mesmo na necessidade de construir uma prática política que considere a imbricação dos sistemas de dominação como o sexismo, o racismo, o heterossexismo e o capitalismo [...]. (tradução nossa $)^{5}$

Para Espinosa-Miñoso (20I4), o pensamento feminista descolonial traz o legado das feministas pós-coloniais como Gayatri Spivak e Chandra Mohanty na crítica à violência epistêmica sofrida pelas mulheres do sul e é influenciado pela tradição teórica do feminismo negro, de cor e terceiro-mundista iniciado nos Estados Unidos, "ao mesmo tempo que busca recuperar o legado crítico das mulheres e feministas afrodescendentes e indígenas que desde a América Latina tem apresentado o problema de sua invisibilidade dentro de seus movimentos"

\footnotetext{
4 "O cimarronaje é o processo de resistência contra o sistema colonial, que consistia de escravos negros que escapavam de seus mestres. Ou seja, qualquer forma de oposição à escravidão no Novo Mundo era chamada cimarronaje.”

Fonte: <https://maestrovirtuale.com/cimarronaje-origem-causas-venezuela-panama/>.

5 “[...] se trata de una posición política que araviesa el pensamiento y la acción individual y colectiva, nuestro imaginarios, nuestros cuerpos, nuestras sxualidades, nuestras formas de actuar y de ser en el mundo y que crea una especie de 'cimarronaje' intelectual, de prácticas sociales y de la construcción de pensamiento propio de acuerdo a experiencias concretas. Se trata del cuestionamiento del sujeto único, al eurocentrismo, al occidentalismo, a la colonialidad del poder, al timpo que reconoce propuestas como la hibridación, la polisemia, el pensamiento otro, subalterno y fronterizo. Estas propuestas críticas el feminismo latinoamericano y caribeño son posiciones de oposición al feminismo ilustrado, blaco, heterosexual, institucional y estatal, pero sobre todo un feminismo que se piensa y repiensa a sí mismo en la necesidad de construir una práctica política que considere la imbricación de los sistemas de dominación como el sexismo, racismo, hetosexismo y el capitalismo [...]” (CURIEL, 2009, p. 3).
} 
(ESPINOSA-MIÑOSO, 2014 , p. 8, tradução nossa). ${ }^{6}$ Ao tentar romper a violência epistêmica e as amarras da colonialidade os feminismos decoloniais e pós-coloniais contribuem para a inserção de novos/as sujeitos/as na construção e na crítica do conhecimento.

Nessa perspectiva, compreendendo a importância dos estudos feministas para a produção do conhecimento e como um espaço de resistência, o presente trabalho tomou como fonte de análise as produções do PPGNEIM/UFBA, o primeiro programa feminista de pós-graduação do Brasil, pertencente ao Núcleo de Estudos Interdisciplinares sobre a Mulher (NEIM), com mais de 30 anos de criação. O PPGNEIM teve suas primeiras turmas de mestrado e doutorado em 2006. Na última seleção (2O20), o programa ofereceu quinze vagas para mestrado e dez vagas para doutorado para alunas brasileiras e uma vaga em cada curso para candidatas estrangeiras. Ademais, também oferece cursos de extensão e especialização com temáticas referentes a gênero, raça e políticas públicas. Em 2009 foi criado o Bacharelado de Estudos Interdisciplinares de Gênero e Diversidade na UFBA, somando mais uma conquista para setores da universidade e para os movimentos sociais.

Desse modo, tomamos como base para esta pesquisa as produções de mestrado e doutorado do PPGNEIM. Foram realizadas buscas no repositório on-line da CAPES e no Catálogo de Dissertações e Teses do programa, nos quais foram encontradas um total de I 24 produções disponíveis para consulta, sendo 92 dissertações e 32 teses. As produções foram defendidas entre 2007-2018. Foram analisados títulos, resumos e palavras-chave de cada produção à procura das seguintes palavras: raça, racismo, relações raciais, negro/negra, branco/branca, branquitude, decolonial, indígena, índios, etnia, etnicidade. Selecionou-se um total de 38 produções entre dissertações e teses, compreendendo 30,43\% das dissertação e 31,25\% das teses (Gráfico I).

\footnotetext{
6 “[...] al tiempo que se propone recuperar el legado crítico de las mujeres y feministas afrodescendientes e indígena que desde América Latina han planteado el problema de su invisibilidad dentro de sus movimientos" (ESPINOSA-MIÑOSO, 2014, p. 8).
} 
Gráfico 1. Total de produções analisadas e de produções selecionadas.

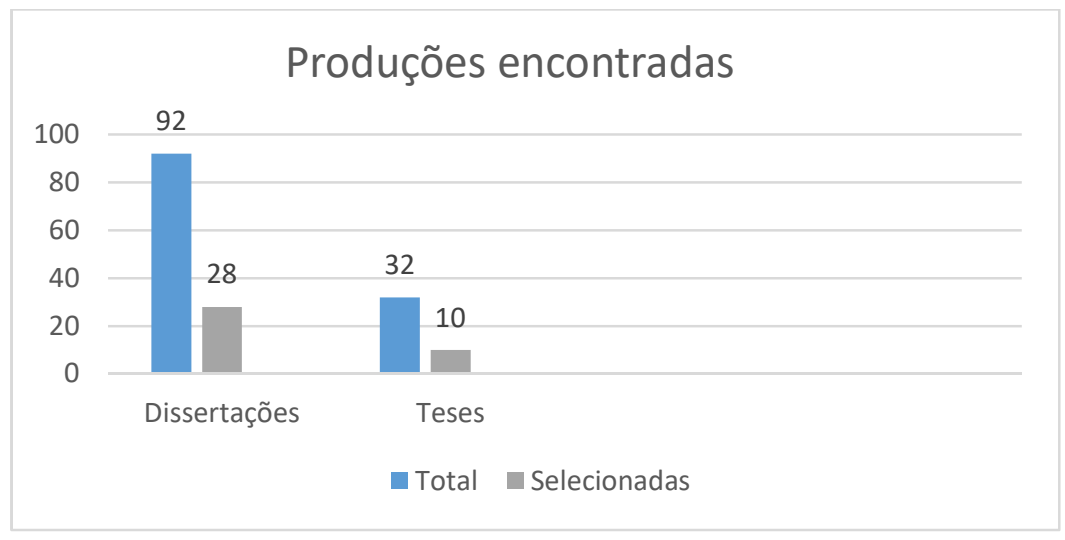

Fonte: Elaboração própria (2019).

Também foi levado em consideração o ano de defesa de cada produção selecionada (Gráfico 2). Observou-se uma pequena evolução entre 2007-20I8. Os anos de 2017 e 2018 apresentaram um maior número de trabalhos selecionados quando comparados aos demais. Em 2017 foi implementada a política de cotas nos programas de pós-graduação da UFBA, que reservou o mínimo de 30\% das vagas ofertadas para alunos e uma vaga a mais em relação ao total de vagas dos cursos para candidatos quilombolas, indígenas, trans (transgênero, transexuais e travestis) e pessoas com deficiência. Ainda que não possamos dimensionar o impacto dessa medida na produção e na crítica do conhecimento, isso já é visível.

Gráfico 2. Número de produções selecionadas de acordo com o ano de defesa (2007-2018).

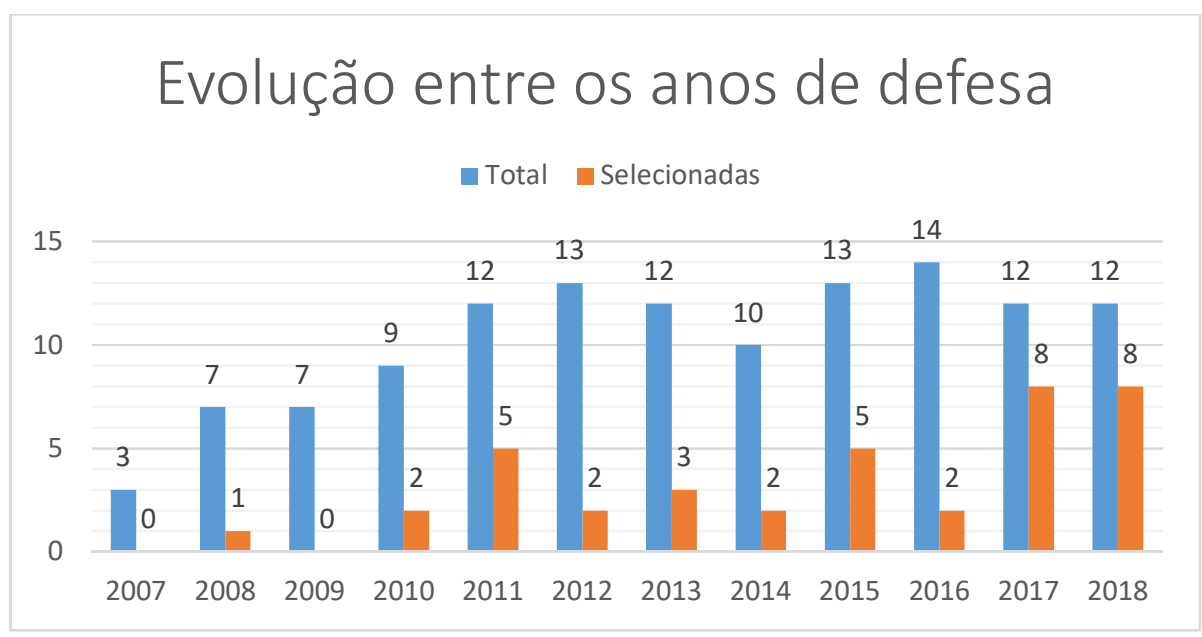

Fonte: Elaboração própria (2019). 
O primeiro trabalho que continha em seu resumo alguma referência a discussões raciais, foi a dissertação de Ana Regina Gomes Reis, Do segundo sexo à segunda onda: discursos feministas sobre a maternidade (2008), que integrou a linha de pesquisa Gênero, Mídia e Discurso. Este trabalho faz parte atualmente da biblioteca on-line do Glefas, um importante grupo de estudos feministas da América Latina que suscita discussões sobre gênero, feminismos, antirracismo e decolonialidade, além de oferecer cursos de formação on-line.

Na Tabela I é possível notar a quantidade de produções defendidas em cada ano, discriminando o total de teses e quantas foram selecionadas pela pesquisa, bem como o total de dissertações e quantas foram selecionadas. Por exemplo, em 2015 houve 13 defesas: três foram teses e dez foram dissertações, entretanto apenas uma tese e quatro dissertações continham em seus resumos alguma das palavras-chave selecionadas.

\section{Tabela 1. Dados levantados.}

\begin{tabular}{|c|c|c|c|c|c|c|}
\hline $\begin{array}{l}\text { Ano de } \\
\text { defesa }\end{array}$ & $\begin{array}{l}\text { Total de } \\
\text { produções } \\
\text { defendidas }\end{array}$ & $\begin{array}{l}\text { Total } \\
\text { de } \\
\text { teses }\end{array}$ & $\begin{array}{l}\text { Teses } \\
\text { selecionadas }\end{array}$ & $\begin{array}{l}\text { Total de } \\
\text { dissertações }\end{array}$ & $\begin{array}{l}\text { Dissertações } \\
\text { selecionadas }\end{array}$ & $\begin{array}{l}\text { Total de } \\
\text { trabalhos } \\
\text { selecionados }\end{array}$ \\
\hline 2008 & 7 & 0 & 0 & 7 & 1 & 1 \\
\hline 2010 & 9 & 2 & 0 & 7 & 2 & 2 \\
\hline 2011 & 12 & 2 & 0 & 10 & 5 & 5 \\
\hline 2012 & 13 & 6 & 1 & 7 & 1 & 2 \\
\hline 2016 & 14 & 3 & 0 & 11 & 2 & 2 \\
\hline 2017 & 12 & 3 & 3 & 9 & 5 & 8 \\
\hline 2018 & 12 & 6 & 3 & 6 & 5 & 8 \\
\hline
\end{tabular}

Fonte: Elaboração própria (2019).

A pequena produção sobre raça, racismo, antirracismo e pensamento crítico decolonial pode ser analisada de três maneiras. A primeira devido à baixa inserção de discentes negras e indígenas no programa de pós-graduação - mesmo que as cotas nos cursos de graduação tenham sido efetivadas em 2012 pelo governo federal e muito antes pela própria UFBA, o acesso desse grupo ainda era limitado. Segundo, o currículo não continha autoras e autores negras/os, indígenas ou latinas/os na mesma proporção que as teorias europeias eram abordadas em sala 
de aula. Pensar em descolonizar as universidades também é pensar em descolonizar o conhecimento e as formas de ensino - não basta criar políticas de cotas se os métodos de ensino e o quadro docente permanecem majoritariamente brancos. Autora desta pesquisa, Amanda Alves foi aluna de mestrado e posteriormente de doutorado do PPGNEIM, portanto foi possível notar a mudança nas ementas das disciplinas de um curso para o outro, quando o programa passou a incluir cada vez mais autoras negras, latinas e de países do sul nas discussões, ainda que muitas vezes tais debates fossem inclusos nas aulas finais das disciplinas teóricas e mais amplamente abordado nas disciplinas optativas. Ressalta-se que é preciso questionar constantemente a maneira como descolonizamos as universidades brasileiras. Tratar as temáticas raciais e decoloniais como mais um apêndice de aprendizado não irá romper com o sistema colonial incutido no país. O Quadro I apresenta a lista de produções selecionadas.

Quadro 1. Autoras e autores selecionadas/os.

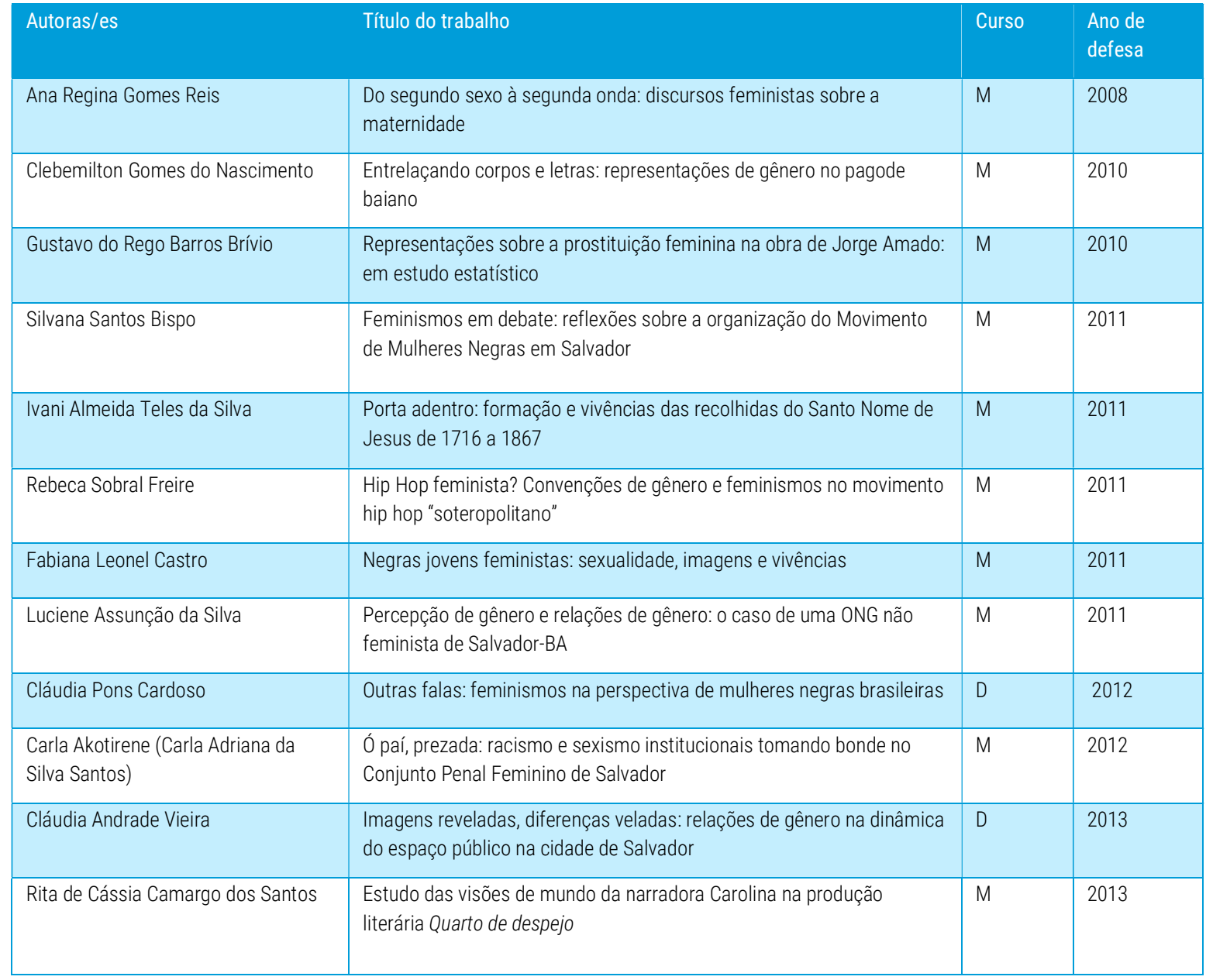




\begin{tabular}{|c|c|c|c|}
\hline Autoras/es & Título do trabalho & Curso & $\begin{array}{l}\text { Ano de } \\
\text { defesa }\end{array}$ \\
\hline Giselle Cristina dos Anjos Santos & $\begin{array}{l}\text { Mulheres negras em Cuba: representações sociais em tempos de crise } \\
\text { (1990-2012) }\end{array}$ & M & 2013 \\
\hline Gilberta Santos Soares & $\begin{array}{l}\text { Sapatos têm sexo? Metáforas de gênero em lésbicas de baixa renda, } \\
\text { negras, no Nordeste do Brasil }\end{array}$ & $\mathrm{D}$ & 2014 \\
\hline Maísa Maria Vale & $\begin{array}{l}\text { Mulheres negras na política: trajetória social e política de mulheres } \\
\text { negras às eleições municipais de Salvador (2008-2012) }\end{array}$ & M & 2014 \\
\hline Juliana Gonçalves Caceres & $\begin{array}{l}\text { À margem das fronteiras legais: trajetórias sociais de mulheres } \\
\text { envolvidas com o tráfico de drogas na Penitenciária Feminina do DF }\end{array}$ & M & 2015 \\
\hline Anni de Novais Carneiro & $\begin{array}{l}\text { Padrões de beleza e elementos identitários de mulheres negras da } \\
\text { periferia de Salvador/Ba }\end{array}$ & M & 2015 \\
\hline Julianin Araújo Santos & $\begin{array}{l}\text { Tornar-se velha: significados de velhice para mulheres idosas na cidade } \\
\text { de Salvador }\end{array}$ & M & 2015 \\
\hline Gilmara Lisboa Santos & $\begin{array}{l}\text { As mulheres negras e brancas no contexto da prostituição: reflexões } \\
\text { sobre as relações étnico/raciais e de gênero no Centro Histórico de } \\
\text { Salvador }\end{array}$ & M & 2015 \\
\hline Silvia Maria Silva Barbosa & $\begin{array}{l}\text { Que poder é esse? Um estudo da constituição e das relações de poder } \\
\text { no llê Asé Ogum Omimkayê }\end{array}$ & $\mathrm{D}$ & 2015 \\
\hline Chirlene Oliveira de Jesus Pereira & $\begin{array}{l}\text { Acesso e utilização de serviços de saúde por mulheres quilombolas } \\
\text { para a promoção da saúde reprodutiva }\end{array}$ & M & 2016 \\
\hline $\begin{array}{l}\text { Nzinga Mbandi (Dayane Nayara } \\
\text { Conceição de Assis) }\end{array}$ & $\begin{array}{l}\text { Dos navios negreiros aos porões da democracia: olhares de mulheres } \\
\text { negras sobre a construção de uma agenda de políticas públicas no } \\
\text { Brasil, de Belo Horizonte-MG a Salvador-BA }\end{array}$ & M & 2016 \\
\hline Luisa Vilharquide Firmino & $\begin{array}{l}\text { Trabalhadoras domésticas em Salvador-BA: primeiras impressões } \\
\text { sobre a Emenda Constitucional no } 72 / 2013 \text { e a Lei Complementar no } \\
\text { 150/2015 }\end{array}$ & M & 2017 \\
\hline Laila Raiana Santana Borges & $\begin{array}{l}\text { As formas que moldam os gêneros: o design como tecnologia de } \\
\text { gênero no projeto de brinquedos infantis }\end{array}$ & M & 2017 \\
\hline Sandro Augusto Silva Ferreira & $\begin{array}{l}\text { Um olhar de gênero sobre o programa de ações afirmativas na UFBA } \\
(2002-2014)\end{array}$ & D & 2017 \\
\hline Claudenilson da Silva Dias & $\begin{array}{l}\text { Identidades trans em candomblés de Salvador: entre aceitações e } \\
\text { rejeições }\end{array}$ & M & 2017 \\
\hline Bianca Muniz Leite & $\begin{array}{l}\text { "Audácia": a Emenda Constitucional 72/2013 a partir das narrativas } \\
\text { sobre as condições de trabalho de mulheres do Sindoméstico Bahia }\end{array}$ & M & 2017 \\
\hline Rebeca Sobral Freire & $\begin{array}{l}\text { Orgulhosamente feministas, necessariamente inconvenientes: uma } \\
\text { "música feminista" ou o que cantam as feministas }\end{array}$ & D & 2017 \\
\hline Francimária Ribeiro Gomes & $\begin{array}{l}\text { Trânsitos musicais e comunicação popular: experiências de } \\
\text { protagonismo de mulheres negras em Cachoeira, BA }\end{array}$ & D & 2017 \\
\hline Izadora Ribeiro Silva Costa & $\begin{array}{l}\text { Notificação de violência contra a mulher na saúde pública: uma questão } \\
\text { de direitos e de gênero }\end{array}$ & M & 2017 \\
\hline
\end{tabular}




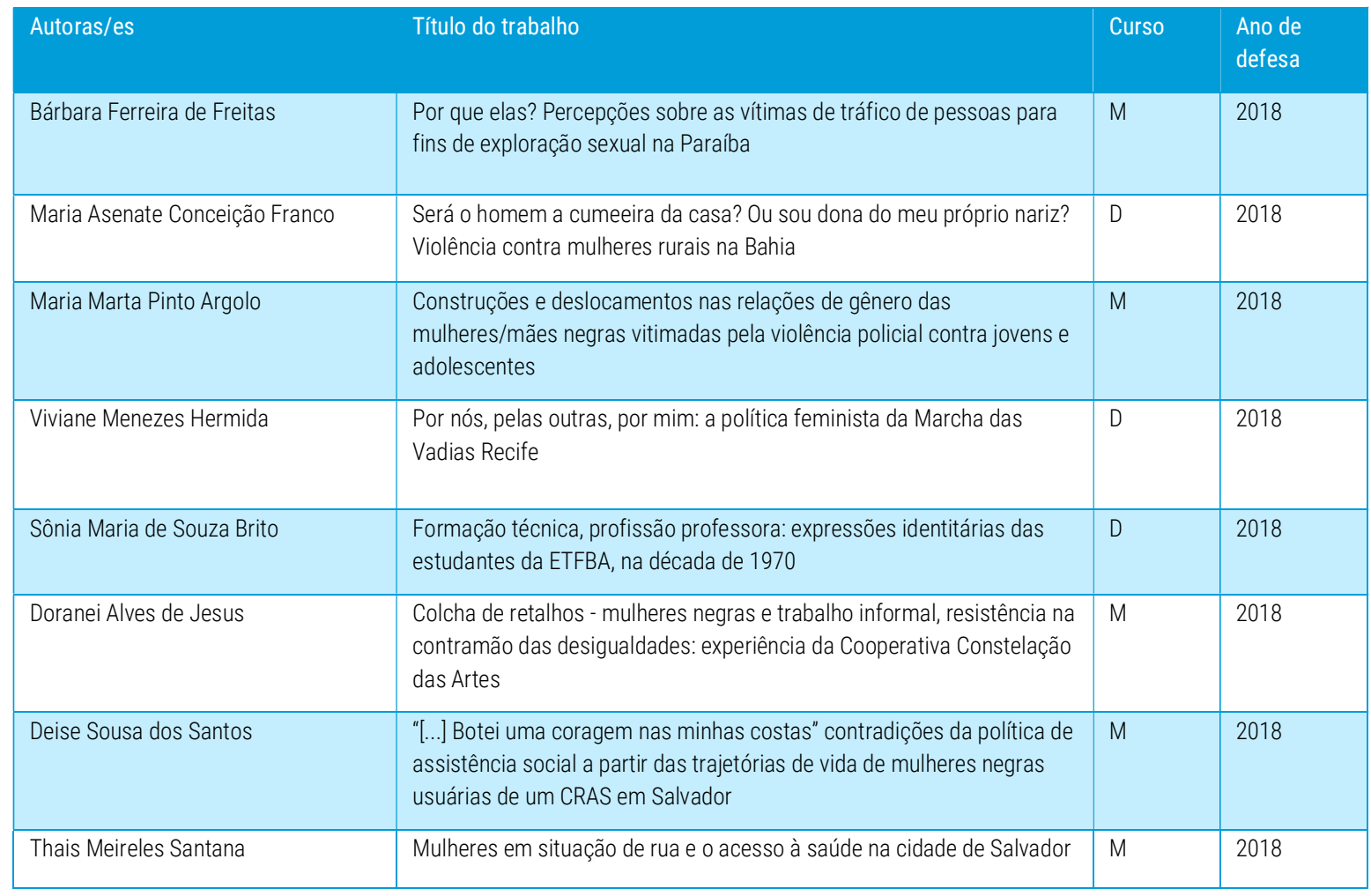

Legenda: $\mathrm{M}=$ mestrado; $\mathrm{D}$ = doutorado.

Fonte: Elaboração própria (2019).

\section{Considerações finais}

Há uma mudança quando observamos os números de trabalhos acadêmicos defendidos com uma discussão antirracista entre os anos de 2007 e 2018. A pequena, mas significativa mudança nos mostra o interesse crescente por parte de discentes da pós-graduação em abordar discussões antirracistas e que questionem o pragmatismo da ciência eurocêntrica. Podemos atribuir essa mudança à inserção de novos/as sujeitos/as por meio das cotas raciais, que fazem da universidade um campo de disputa e embate político, bem como um espaço de resistência. Também podemos atribuir isso aos muitos desdobramentos dos movimentos sociais e ao uso qualificado das Tecnologias de Informação e Comunicação (TICs), fazendo circular informações e pressionando o mercado editorial a incorporar estratégias que lhes beneficiem, como os recentes desdobramentos dentro dos próprios movimentos feministas, negro e indígena, que vêm ganhando força com a juventude que ambiciona abordagens mais qualificadas e sistêmicas.

Para fins de conclusão, ressalta-se a importância da política de cotas nas instituições de ensino superior para a promoção de novas epistemologias, inclusive as feministas e decoloniais. Aliam-se aos esforços iniciados novas possibilidades interpretativas, como: a aproximação com 
discentes do Bacharelado de Estudos de Gênero e Diversidade; ${ }^{7}$ os trânsitos entre cursos disciplinares e interdisciplinares; a estrutura produtivista sobre a avaliação da pós-graduação, que exige maior participação em eventos científicos, sendo estes espaços de publicação; entre outras. Assim, para incorporar as outras bases e fontes formativas desses/as sujeitos/as, para além dos conhecimentos apropriados pela universidade, são necessários novos reconhecimentos de outras narrativas e bases epistêmicas, bem como a ampliação dos debates que também fazem parte desses processos de disputas, e que têm nas políticas de citação também outro elemento importante de reflexão, mas cujos desdobramentos já nos permitem ao menos iniciar este debate. Nossa esperança é que, da mesma maneira que entendemos como estratégico que os estudos sobre gênero e raça não sejam responsabilidades exclusivas dos espaços acadêmicos em que docentes se reúnem, constituindo grupos de pesquisas com essas finalidades declaradas, mas, ao contrário, que tais conteúdos possam embasar novas condutas entre intelectuais acadêmicas.

\section{Referências}

ARTES, A.; MENA-CHALCO; J. Expansão da temática relações raciais no banco de dados de teses e dissertações da Capes. Educ. Pesqui., São Paulo, v. 43, n. 4, p. I22 I-I238, out./dez. 2017. Disponível em: $<$ http://www.scielo.br/pdf/ep/v43n4/1517-9702-ep-Si5179702 201702152528.pdf $>$. Acesso em: 21 abr. 2019.

BARRETO, P.C. da S. Múltiplas vozes: racismo e anti-racismo na perspectiva dos universitários de São Paulo. Salvador: EDUFBA, 2008.

BENTO, M. A. S. Branquitude e poder: a questão das cotas para negros. In: SANTOS, S. A. dos (Org.). Ações afirmativas e combate ao racismo nas Américas. Brasília: Ministério da Educação; UNESCO, 2005. p. 165-177.

BIDASECA, K. Perturbando el texto colonial: los estúdios (pos)coloniales en América Latina. I. ed. Buenos Aires: SB, 2010.

BRASIL. Lei n. I2.7II, de 29 de agosto de 20I2. Dispõe sobre o ingresso nas universidades federais e nas instituições federais de ensino técnico de nível médio e dá outras providências. Diário Oficial [da] República Federativa do Brasil, Brasília, DF, 29 ago. 2012. Disponível em: $<$ http://www.planalto.gov.br/ccivil_03/_ato2OII-2OI4/20I2/lei/li27II.htm $>$. Acesso em: 5 mar. 2019.

\footnotetext{
${ }^{7}$ Ver: <www.generoediversidade.ufba.br>.
} 
CARVALHO, J. J. de. Encontro de saberes e descolonização: para uma refundação étnica, racial e epistêmica das universidades brasileiras. In: BERNADINO-COSTA, J.; MALDONADOTORRES, N.; GROSFOGUEL, R. (Orgs.). Decolonialidade e pensamento afrodiaspórico. I. ed. Belo Horizonte: Autêntica, 2018. p. 79-IO6.

CASTILLO, R. A. H. Feminismos poscoloniales: reflexiones desde el sur del Río Bravo. In: NAVAZ, L. S.; CASTILLO, R. A. H.(Eds.). Descolonizando el feminismo: teorías y prácticas desde los márgenes. 2. ed. Madrid: Ediciones Cátedra; Universidad de Valéncia; Instituto de la Mujer, 20II. p. 75-II6.

CURIEL, O. Descolonizando el feminismo: una perspectiva desde America Latina y el Caribe. In: COLOQUIO LATINOAMERICANO SOBRE PRAXIS Y PENSAMIENTO FEMINISTA, I., 2009, Buenos Aires. Anais... Buenos Aires: 2009. Disponível em: $<$ http://feministas.org/IMG/pdf/Ochy_Curiel.pdf >. Acesso em: I3 jun. 2018.

ESPINOSA-MIÑOSO, Y. Una crítica descolonial a la epistemología feminista crítica. El Cotidiano - Género: Visiones y Debates Necesarios, n. I84, p. 7-I2, mar./abr. 2014.

ANDIFES - Associação Nacional dos Dirigentes das Instituições Federais de Ensino Superior. Fórum Nacional de Pró-reitores de Assuntos Comunitários e Estudantis. V Pesquisa Nacional de Perfil Socioeconômico e Cultural dos Estudantes de Graduação. Uberlândia: FONAPRACE/ANDIFES, 2019.

GOMES, N. L. O movimento negro educador: saberes construídos nas lutas por emancipação. Petrópolis, RJ: Vozes, 2017.

GUIMARÃES, A. S. A. Como trabalhar com "raça” em sociologia. Educação e Pesquisa, São Paulo, v. 29, n. I, p. 93-I07, jan./jun. 2003.

IBGE - INSTITUTO BRASILEIRO DE GEOGRAFIA E ESTATÍSTICA. 20I8. Pesquisa Nacional por Amostra de Domicílios Contínua. Educação 2017. Disponível em:

$<$ https://biblioteca.ibge.gov.br/visualizacao/livros/livioI576_informativo.pdf $>$. Acesso em: 30 jan. 2020.

LAZARO, A. Observatório da Lei de Cotas: proposta de avaliação da Lei n. I2.7II/2OI2. In: ARTES, A.; UNBEHAUM, S.; SILVÉRIO, V. (Orgs.). Ações afirmativas no Brasil: reflexões e desafios para a pós-graduação. São Paulo: Cortez; Fundação Carlos Chagas, 20I6. p. I25-156. Vol. I. 
MIGNOLO, W. Os esplendores e as misérias da "ciência": colonialidade, geopolítica do conhecimento e pluri-versalidade epistémica. In: SANTOS, B. de S. (Org.). Conhecimento prudente para uma vida decente: discurso sobre as ciências revisitado. São Paulo: Cortez, 2004. p. 667-7IO.

MOHANTY, C. Bajo los ojos de Occidente: academia feminista y discursos coloniales. In: NAVAZ, L. S.; HERNÁNDEZ, R. A. (Orgs.). Descolonizando el feminismo: teorías y prácticas desde los márgenes. 2. ed. Madrid: Ediciones Cátedra, $201 \mathrm{I}$.

OLIVEN, A. C. Ações afirmativas, relações raciais e política de cotas nas universidades: uma comparação entre os Estados Unidos e o Brasil. Educação, Porto Alegre - RS, v. 6I, p. 29-5I, 2007.

QUIJANO, A. Colonialidad y modernid-racionalidad. In: BONILLA, H. (Org.). Los conquistados: I492 y la población indígena de las Américas. Bogotá: Tecer Mundo Ediciones; FLACSO, I992. p. 437-449.

QUIJANO, A. Colonialidade do poder e classificação social. In: SANTOS, B. de S.; MENESES, M. P.(Orgs.). Epistemologias do Sul. São Paulo: Cortez, 20IO. p. 84-I30.

QUIJANO, A. Colonialidade do poder, eurocentrismo e América Latina. In: LANDER, E. (Org.). A colonialidade do saber: eurocentrismo e ciências sociais. Perspectivas latino-americanas. Buenos Aires: Clacso, 2005. p. I07-I26. (Colección Sur Sur.)

ROBAINA, T. F. A luta contra a discriminação racial em Cuba e as ações afirmativas: convite à reflexão e ao debate. In: SANTOS, S. A. dos (Org.). Ações afirmativas e combate ao racismo nas Américas. Brasília: Ministério da Educação; UNESCO, 2005. p. 359-385.

SANTOS, J. T. dos; QUEIROZ, D. M. O impacto das cotas na Universidade Federal da Bahia (2004-2OI2). In: SANTOS, J. T. dos (Org.). O impacto das cotas nas universidades brasileiras (200420I2). Salvador: CEAO, 2OI3. p. 37-66.

SILVÉRIO, V. R.; MEDEIROS, P. M. Ação afirmativa para negros e indígenas: um ensaio sobre a crise do discurso civilizacional e a reorientação nas políticas públicas de inclusão no Brasil. In: ARTES, A.; UNBEHAUM, S.; SILVÉRIO, V. (Orgs.). Ações afirmativas no Brasil: reflexões e desafios para a pós-graduação. São Paulo: Cortez; Fundação Carlos Chagas, 20I6. p. 6I-92. Vol. 2.

SOUZA, Â. M. F. L. e et al. Catálogo de dissertações e teses PPGNEIM/UFBA. Salvador: UFBA, 2018. SPIVAK, G. C. Pode o subalterno falar? Tradução Sandra Regina Goulart Almeida, Marcos Pereira Feitosa, André Pereira Feitosa. Belo Horizonte: Editora UFMG, 2010. 